\title{
REALIDAD Y PERSPECTIVA DEL DERECHO DE SUFRAGIO ACTIVO DE LAS PERSONAS CON DISCAPACIDAD INTELECTUAL
}

\author{
ALBERTO ANGUITA SUSI \\ Profesor Titular de Derecho Constitucional \\ Universidad de Jaén
}

\section{SUMARIO}

I. Introducción. II. Breve referencia a la participación en los asuntos públicos de las personas discapacitadas en el marco jurídico internacional y europeo. III. La protección de los discapacitados en la Constitución española: propuesta de reforma. IV. Los límites del derecho de sufragio activo de las personas discapacitadas en la LOREG. V. Algunas consideraciones preliminares sobre la reforma de la LOREG de 2018. VI. Conclusiones.

\section{INTRODUCCIÓN}

La interpretación de los derechos fundamentales y libertades públicas de conformidad con el principio pro libertate, unido a la realización efectiva de la igualdad participativa en los asuntos públicos (art. 9.2 CE), constituyen el fundamento del libre desarrollo de la personalidad y la dignidad en el ejercicio de los derechos fundamentales (art. 10.1 CE). En este sentido, «el respeto a la dignidad de las personas con discapacidad exige el reconocimiento de su libertad moral, característica predicable de todos los ciudadanos, y que se concreta en la facultad para autodeterminarse, para forjar su propio destino vital mediante la adopción autónoma de decisiones personalísimas (...) la garantía de la dignidad humana reclama no solo el reconocimiento de la titularidad formal de los derechos, sino especialmente la igualdad en el ejercicio de los mismos por parte de las personas con discapacidad ${ }^{1}$.

1 Tomamos la cita de Álvarez García H., «La tutela constitucional de las personas con discapacidad», RDP, n. ${ }^{\circ} 100,2017$, p. 1041. 
Es cierto que la capacidad de obrar está más limitada en determinadas personas, debido a sus circunstancias personales, pero esto no debe llevar a adoptar una visión «paternalista» a la hora de proteger y promover los derechos de ciertos colectivos. Las condiciones de ejercicio de los derechos fundamentales no pueden convertirse en un obstáculo insalvable, de aquí que carezca de fundamento la exigencia de requisitos o límites adicionales, cuando de lo que se trata es de propiciar, de una manera flexible y adaptada, dicho ejercicio a las circunstancias personales del sujeto activo del derecho.

En este sentido existen, simplificando, dos modelos a la hora de tratar la discapacidad: médico y social ${ }^{2}$. Desde el punto de vista del primero, la discapacidad se anuda a las circunstancias personales del sujeto derivadas de una deficiencia y se sustenta en la normalización de dichas personas al objeto de conseguir su integración social. Lo que significa que las posibles limitaciones a la hora de ejercer ciertos derechos es una consecuencia natural e inevitable. El segundo modelo, en cambio, entiende que la sociedad no es capaz de asimilar la diversidad debido a la imposición de unos parámetros físicos y psíquicos estereotipados.

Por lo que respecta al ejercicio concreto de derechos por parte de personas discapacitadas se barajan también dos modelos: de status y funcional. Centrándonos en este último, «las personas con discapacidad intelectual y psicosocial pueden ser incapaces de tomar decisiones en unos ámbitos y capaces en otros, por lo que aboga por una evaluación específica de su idoneidad para el ejercicio del derecho de sufragio» ${ }^{3}$. Este modelo plantea, en la práctica, una serie de dificultades a la hora de concretar el estándar de capacidad, el método empleado para evaluarla y el alto grado de indeterminación que se dejaría a los sujetos encargados de su ejecución.

El ejercicio del derecho al sufragio activo por personas con alguna discapacidad no se resuelve, por tanto, desde una perspectiva restrictiva o prohibitiva, sino más bien, desde la adaptabilidad y modulación, para lo cual habrá que concretar el margen de maniobra con el que cuenta al respecto el legislador.

En el ámbito de la participación política las posibles limitaciones legales a la capacidad de obrar deberían concretarse en la «capacidad política», definida por algún autor como la «capacidad para autodeterminarse, para intervenir en la formación de las diferentes opciones políticas y para poder pronunciarse sobre ellas (...) para discernir entre unas y otras propuestas» ${ }^{4}$.

2 Seguimos en este punto a Cuenca Gómez P., «El derecho al voto de las personas con discapacidad intelectual y psicosocial. La adaptación de la legislación electoral española a la Convención Internacional de los derechos de las personas con discapacidad», Derechos y Libertades, n. ${ }^{\circ} 38,2018$, pp. 174 y 175.

3 Cuenca Gómez P., «El derecho al voto de las personas con discapacidad intelectual y psicosocial. La adaptación de la legislación electoral española a la Convención Internacional de los derechos de las personas con discapacidad», op. cit. p. 183.

4 Presno Linera M.A., «La titularidad del derecho de participación política», Boletín Mexicano de Derecho Comparado, n. ${ }^{\circ} 114,2002$, p. 552. Citado por LEón Alonso M., «Los derechos de participación política de las personas con discapacidad: el derecho de voto», REDFs, n. ${ }^{\circ}$ 24, 2014, pp. 167 a 193. 
Esta capacidad, sin embargo, lejos de constituir un límite externo al ejercicio del derecho de sufragio activo, debe ser entendida como un elemento propio del contenido esencial, y es precisamente el legislador quien debe modular y concretar el alcance de dicho contenido. Aquí radica, como veremos, el fondo de la polémica.

\section{BREVE REFERENCIA A LA PARTICIPACIÓN EN LOS ASUNTOS PÚBLICOS DE LAS PERSONAS DISCAPACITADAS EN EL MARCO JURÍDICO INTERNACIONAL Y EUROPEO}

En el plano internacional, tanto el art. 21 de la Declaración Universal de Derechos Humanos de 1948, como el art. 25 del Pacto Internacional de Derechos Civiles y Políticos de 1966, proclaman sin restricciones el derecho a participar en los asuntos públicos mediante los correspondientes procesos electorales. De hecho, los protocolos interpretativos de estas normas ponen de manifiesto que el ejercicio del derecho de sufragio debe responder a criterios objetivos y razonables, sin que quepan restricciones indebidas o desproporcionadas a su efectivo ejercicio ${ }^{5}$.

Estas previsiones se vieron ratificadas con la aprobación, en diciembre de 2006, de la Convención sobre los Derechos de las Personas con Discapacidad, mediante Resolución 61/106 de la Asamblea General de Nacionales Unidas ${ }^{6}$. Este texto normativo resulta muy explícito, a diferencia de otras normas sobre la materia que se expresan en un tono finalista. Además, la Convención marca un claro punto de inflexión dado que la discapacidad deja de ser tratada como un derecho prestacional, relativo al bienestar social, para convertirse en un derecho humano, que tiene que ver con la dignidad y el libre desarrollo de la personalidad de las personas discapacitadas. Dicho de otra forma: la discapacidad es llevada al ámbito de los derechos fundamentales, reformulando así su clásica regulación jurídica en el ámbito de los meros principios de la política económica y social.

Desde esta perspectiva, el art. 1 proclama el propósito de «promover, proteger y asegurar el goce pleno y en condiciones de igualdad de todos los derechos

5 Pascual Planchuelo V.C., «El derecho de voto de las personas con discapacidad y, en especial, de las personas con discapacidad psíquica o intelectual en Derecho Internacional. Su recepción en España», Revista Española de Discapacidad, n. ${ }^{\circ}$ 4, 2016, pp. 101 a 122.

6 La Convención fue ratificada por España el 3 de mayo de 2008. Véase desde una panorámica general a Domínguez Alonso A.P., «La incorporación en el Derecho de la Unión Europea de la Convención de la ONU sobre los derechos de las personas con discapacidad», $R G D A$, n. ${ }^{\circ} 29,2012$, pp. 1 a 23 ; y AA.VV (Dirs. Pérez Bueno L.C., Lidón Heras L.), La Convención Internacional sobre los derechos de las personas con discapacidad 2006/2016: una década de vigencia, Ediciones Cinca, Madrid, 2016. En cuanto a la participación política de las personas con discapacidad: Lidón Heras L., «El derecho de participación política de las personas con discapacidad: el caso de España tras más de una década de vigencia de la Convención Internacional sobre los derechos de las personas con discapacidad», Revista Chilena de Derecho y Ciencia Política, n. ${ }^{\circ} 2,2017$, pp. 56 a 86. 
humanos y libertades fundamentales por todas las personas con discapacidad, y promover el respeto a su dignidad inherente». Se trata, como puede apreciarse, de un reconocimiento pleno y efectivo del ejercicio, en condiciones de igualdad, de las personas con discapacidad a participar plenamente en la vida política, tal y como establece el art. 29 de la Convención, que también reconoce el derecho de sufragio pasivo, un aspecto, dicho sea de paso, que no ha suscitado la atención suficiente por la normativa internacional y europea y sobre el cual cabría incidir, en orden a conseguir la plena integración y participación efectiva de las personas discapacitadas.

En la esfera europea, el art. 26 de la Carta Europea de Derechos Fundamentales de la Unión Europea, de 7 de diciembre de $2000^{7}$, dedicado a la integración de las personas con discapacidad, dispone que «La Unión reconoce y respeta el derecho de las personas discapacitadas a beneficiarse de medidas que garanticen su autonomía, su integración social y profesional y su participación en la vida de la comunidad».

Este precepto, cuyo contenido recuerda al art. 9.2 de nuestra Carta Magna, plantea la discapacidad desde una doble perspectiva: individual (autonomía) y colectiva (integración), lo que proyecta los derechos de las personas discapacitadas, más allá de su ejercicio individual, hacia la plena integración y participación efectiva en la vida política, económica y social.

Esta perspectiva venía auspiciada por el art. 15 de la Carta Social Europea, tras su reforma de 1996, en virtud de la cual los Estados parte se comprometen a adoptar una serie de medidas tendentes a «garantizar a las personas minusválidas, con independencia de su edad y de la naturaleza y el origen de su minusvalía, el ejercicio efectivo del derecho a la autonomía, a la integración social y a la participación en la vida de la comunidad» ${ }^{8}$.

En clara sintonía con este marco normativo, las Sentencias del TEDH de 30 de marzo de 2004 (Asunto Hirst vs. Reino Unido) y de 20 de mayo de 2010 (Asunto Alajos Kiss vs. Hungría) se decantan por una interpretación amplia del ejercicio del derecho de sufragio, entendido como un elemento de inclusión e integración de los colectivos y su participación en la vida democrática y social. Las posibles limitaciones del derecho de sufragio deben ser reguladas de forma excepcional, personalizada y de acuerdo con las aptitudes y capacidades individuales de cada sujeto, de tal forma que cualquier restricción indiscriminada del

7 El texto de la Carta fue adaptado para su incorporación al Tratado de Lisboa, entrando en vigor el 1 de diciembre de 2009.

8 Esta versión revisada de la Carta, que es la que introduce la plena autonomía y participación en la vida de la comunidad de las personas con discapacidad, más allá de la esfera de la educación y el empleo, sigue todavía pendiente de ratificación por España. De hecho, el 1 de febrero de 2019 el Consejo de Ministros adoptó un Acuerdo remitiendo el texto revisado para su ratificación por las Cortes Generales, pero el mismo quedó sin efecto debido a la disolución anticipada de las Cortes y la posterior celebración de las elecciones generales de 28 de abril de 2019. 
derecho de sufragio, sin una evaluación judicial individual y exclusivamente basada en una discapacidad intelectual, resultaría incompatible con el pleno ejercicio de dicho derecho.

\section{LA PROTECCIÓN DE LOS DISCAPACITADOS EN LA CONSTITUCIÓN ESPAÑOLA: PROPUESTA DE REFORMA}

El art. 49 CE señala que «los poderes públicos realizarán una política de previsión, tratamiento, rehabilitación e integración de los disminuidos físicos, sensoriales y psíquicos a los que prestarán la atención especializada que requieran y los ampararán especialmente para el disfrute de los derechos que este Título otorga a los ciudadanos».

Este precepto se inspiró claramente en el art. 71.2 de la Constitución de Portugal, el cual proclama: «El Estado se obliga a realizar una política nacional de prevención y de tratamiento, rehabilitación e integración de los ciudadanos portadores de deficiencia, y de apoyo a sus familias; a desarrollar una pedagogía que sensibilice a la sociedad en cuanto a los deberes de respeto y solidaridad para con ellos y a asumir la carga de la realización efectiva de sus derechos, sin perjuicio de los derechos y deberes de los padres o tutores».

La regulación constitucional de la discapacidad es de alguna forma deudora del momento y el contexto en el que el precepto fue redactado, limitándose a consagrar una serie de medidas sociales que no viene sino a poner de manifiesto una visión prestacional, alejada por tanto del acervo propio del ejercicio de los derechos fundamentales.

Buena muestra de ello es la arcaica denominación — disminuidos- utilizada por el constituyente español para referirse a las personas discapacitadas, cuando la Constitución de Portugal ya hablaba en 1976 de ciudadanos con deficiencias. La semántica del precepto conecta claramente con el contenido del mismo que recoge la concepción imperante en aquélla época de la discapacidad como un problema, donde los prejuicios sociales consideraban a los discapacitados como personas inferiores, necesitadas de protección e incapaces de integrarse socialmente?

De lo anterior se desprende que si bien la terminología empleada por el constituyente español alude claramente al «modelo médico o rehabilitador» en cuanto al tratamiento de la discapacidad se refiere, no es menos cierto que también introduce elementos propios del «modelo social» al referirse a la integración y al disfrute de los derechos por parte de las personas discapacitadas.

A partir de la teoría del disfrute pleno de los derechos fundamentales habría que interpretar y entender el ejercicio de los derechos de las personas

9 Állvarez García H., «La tutela constitucional de las personas con discapacidad», op. cit. p. 1039. 
discapacitadas, adoptando en consecuencia una renovada visión del art. 49 CE. Un precepto que de una forma intuitiva conectaba precisamente la discapacidad con el disfrute y el ejercicio de los derechos fundamentales ${ }^{10}$.

De esta manera puede afirmarse que «los derechos fundamentales son los instrumentos jurídicos idóneos para que también las personas con discapacidad puedan, en la mayor medida posible, diseñar y desarrollar libremente, en el ejercicio autónomo de su voluntad, sus propios planes de vida (...) son pues ventanas abiertas para incorporación de las nuevas dimensiones del modelo social que permitirán que el propio texto constitucional se pueda constituir en el instrumento más eficaz para garantizar el libre desarrollo de la personalidad de las personas con discapacidad $»^{11}$.

En esta línea cabe destacar el Anteproyecto de reforma del art. 49 CE, aprobado por Consejo de Ministros el 7 de diciembre de 2018, a iniciativa de la Vicepresidenta del Gobierno, Dña. Carmen Calvo, a partir de la propuesta de la Comisión para las Políticas Integrales de la Discapacidad del Congreso de los Diputados.

Dicho Anteproyecto proponía la siguiente redacción para el citado precepto: «1. Las personas con discapacidad son titulares de los derechos y deberes previstos en este Título en condiciones de libertad e igualdad real y efectiva, sin que pueda producirse discriminación. 2. Los poderes públicos realizarán las políticas necesarias para garantizar la plena autonomía personal e inclusión social de las personas con discapacidad. Estas políticas respetarán su libertad de elección y preferencias (...)».

La propuesta de reforma art. $49 \mathrm{CE}$ constituye un claro ejemplo de constitucionalizar dentro del acervo propio de los derechos fundamentales los derechos sociales, en la medida en que se sustituye la perspectiva objetiva de las clásicas políticas sociales de protección por una visión subjetiva del ejercicio de los derechos por ciertos colectivos.

Es más, dicho ejercicio se condiciona tanto a la igualdad real y efectiva del art. 9.2 CE como a la igualdad formal proclamada en el art. $14 \mathrm{CE}$. De hecho, puede afirmarse que la propuesta de reforma constitucional persigue que ambos preceptos sean constitucionalizados en el Capítulo III de la CE.

La perspectiva subjetiva del ejercicio de los derechos por personas discapacitadas queda ratificada por el hecho que en la propuesta se garantice tanto la plena autonomía personal — dimensión subjetiva— como la inclusión social —dimensión comunitaria-.

10 Sobre la evolución en cuanto a las medidas adoptadas para hacer efectivo el ejercicio de este derecho por personas con discapacidad véase GÁLvez MUÑoz L.A., «El régimen de la participación electoral de las personas con discapacidad en los cuarenta años de democracia», RDP, n. ${ }^{\circ}$ 100, 2017, pp. 1057 a 1096.

11 Campoy Cervera I., «La discapacidad y su tratamiento conforme a la Constitución Española de 1978», en AA.VV (Coords. Campoy Cervera I., PAlacios Rizzo A.)., Igualdad, no discriminación y discapacidad. Una visión integradora de las realidades española y argentina, Dykinson, Madrid, 2007, pp. 169 y 170. 
En todo caso, una cosa es hablar, en el plano teórico, de los derechos sociales fundamentales y otra, muy distinta, articular constitucionalmente hablando esta posibilidad. La distinta naturaleza jurídica de los derechos constitucionalizados está anudada, asimismo, al nivel de garantías que el diseño constitucional les atribuye, de tal manera que no cabría una suerte de «fundamentalización indirecta» de los derechos sociales.

Para ello sería necesario reformar la Constitución por la vía del art. 168 y ampliar, en consecuencia, el catálogo de los derechos fundamentales en sentido estricto, incluyendo algunos de naturaleza social, en lugar de mantener topográficamente los derechos y, al amparo del art. $167 \mathrm{CE}$, extenderles las garantías del art. $53 \mathrm{CE}$. El art. $168 \mathrm{CE}$ está pensado para reformar todos aquellos aspectos que «afecten» a los derechos fundamentales de máxima protección, por lo que quedaría dentro de su ámbito de acción las garantías del art. $53 \mathrm{CE}^{12}$.

Pero con independencia de estas cuestiones técnicas, lo cierto es que la propuesta de reforma del art. 49 CE podría ser considerada como una suerte de «cláusula constitucional», similar al art. 13 CE para el ejercicio de los derechos por los extranjeros en España, que otorgaría la suficiente cobertura constitucional $y$, por ende, seguridad jurídica, a una futura regulación legal que previera la participación política de los discapacitados intelectuales. A este tema dedicamos, precisamente, el siguiente epígrafe.

\section{LOS LÍMITES DEL DERECHO DE SUFRAGIO ACTIVO DE LAS PERSONAS DISCAPACITADAS EN LA LOREG}

\section{Regulación y aplicación jurisdiccional}

El tenor literal del art. 3.1 b) de la LOREG señalaba antes de su reforma que carecen de derecho de sufragio «los declarados incapaces en virtud de sentencia judicial firme, siempre que la misma declare expresamente la incapacidad para el ejercicio del sufragio». Por su parte, el art. 3.2 disponía que «a los efectos previstos en este artículo, los jueces y tribunales que entiendan de los procedimientos de incapacitación o internamiento deberán pronunciarse expresamente sobre la incapacidad para el ejercicio del sufragio».

Resulta curioso, en una primera aproximación a esta disposición, que a diferencia de lo que suele ser habitual, esto es, que las normas limitadoras de la capacidad de una persona con discapacidad persigan la protección de sus intereses, el mencionado precepto contenga una disposición restrictiva, limitativa

12 En este sentido resulta paradigmática la propuesta, y el consiguiente debate, del Prof. Lorenzo García ante la Comisión para las políticas integrales de la discapacidad en el Congreso de los Diputados, al hilo de los trabajos preparatorios para la reforma del art. 49 CE. (Vid. DSCD, n. ${ }^{\circ} 653$, de 31 de octubre de 2018, pp. $5,7,11$ y 12$)$. 
de la titularidad. Conviene recordar, a este respecto, que la falta de capacidad para el ejercicio de un derecho no supone la inhabilitación para ser titular del mismo. Precisamente y dado que el derecho de participación política conecta con la democracia misma, debe partirse de la premisa de que todos los ciudadanos son titulares, como integrantes del cuerpo electoral, de dicho derecho. Cuestión distinta es que no todos ellos puedan ejercerlo de forma adecuada y concreta.

En este sentido, convendría preguntarse si las posibles limitaciones o restricciones son proporcionadas y, sobre todo, coherentes entre el fin buscado y las medidas adoptadas al respecto. La respuesta que, prima facie, puede darse es que «resulta muy difícil argumentar que se priva de él al incapacitado para evitarle un perjuicio. Precisamente el derecho de sufragio permite a su titular, en conexión con su inalienable libertad ideológica, decantarse por cualquiera de las formaciones políticas que legalmente se presenten a los comicios» ${ }^{13}$.

Dicho de otra forma, los posibles errores o decisiones desviadas es algo que afecta a todos los ciudadanos, sin que pueda derivarse de ello que las personas con discapacidad pueden votar de forma desacertada y, sobre todo, que ello sea un perjuicio para sus intereses.

Esta situación recuerda, de alguna forma, a la declaración de inconstitucionalidad de la Ley 8/2000, reguladora de los derechos de los extranjeros en España y su integración social, en virtud de la cual el Tribunal Constitucional vino a decir que el legislador orgánico debe modular las condiciones de ejercicio de los derechos fundamentales por parte de los extranjeros en España, pero lo que no puede hacer es negar, de forma desproporcionada, la titularidad de algunos de ellos condicionándolos a su situación administrativa.

De esta forma, puede afirmarse que «las personas cuya falta de capacidad haya sido demostrada en el transcurso de un proceso, no carecen por ello del derecho de sufragio. En todo caso, y si así lo decide la autoridad judicial competente, no podrán votar por falta de capacidad intelectiva para ello» ${ }^{14}$.

El legislador no imponía la privación del sufragio como regla general a cualquier persona incapaz sino sólo a aquéllas declaradas por el juez dependiendo de su grado de discernimiento. En esta línea, la Instrucción 3/2010, de 29 de noviembre, de la Fiscalía General del Estado ${ }^{15}$, señalaba que «resulta evidente que su pérdida (del sufragio) no es una consecuencia necesaria de la declaración de incapacidad de una persona, de suerte que aún cuando haya sido modificada la

13 Seguimos en este punto a Díaz Alabart S., «El derecho al sufragio activo de las personas con discapacidad. La visión civilista», Revista de Derecho Privado, n. ${ }^{\circ}$ 1, 2012, p. 13.

14 Vid. León Alonso M., «Los derechos de participación política de las personas con discapacidad: el derecho de voto», op. cit. p. 177.

15 Resulta significativo el título de la Instrucción: «La necesaria fundamentación individualizada de las medidas de protección o apoyo en los procedimientos sobre determinación de la capacidad de las personas». 
capacidad, el afectado puede conservar su derecho de sufragio, salvo que se le prive motivada y expresamente de este derecho» ${ }^{16}$.

La continuidad de estas medidas queda refrendada en la Comunicación de la Fiscalía del Tribunal Supremo, de 4 de julio de 2012, en cuya Conclusión Sexta se determinaba que «los Srs. Fiscales cuidarán especialmente de que la privación del derecho de sufragio únicamente se lleve a efecto cuando resulte necesario en atención a la situación de la persona cuya capacidad se cuestiona. Dicha medida requerirá el pronunciamiento expreso en la sentencia, en la cual deberá razonarse acerca de la valoración de las circunstancias en las que se fundamenta la privación del derecho de sufragio».

Por lo que se refiere a la interpretación y aplicación jurisdiccional de la LOREG cabe afirmar que durante gran parte de su vigencia los tribunales anudaban, como regla general, a los procesos de incapacitación la privación del derecho de sufragio, utilizando para ello resoluciones-tipo o cláusulas de estilo carentes de justificación. Esta forma de proceder obedecía a una visión paternalista en virtud de la cual se consideraba que la sustitución de la voluntad personal equivalía a un mayor grado de protección de las personas discapacitadas.

Esta concepción, sin embargo, comenzó a cambiar a raíz de la Sentencia de la Sala Primera, de lo Civil, del Tribunal Supremo, de 29 de abril de 2009, según la cual la incapacitación no debe condicionar o alterar la titularidad de los derechos, pudiendo llegar a condicionar, en todo caso, su ejercicio. Esta nueva línea jurisprudencial supuso la eliminación del sistema de sustitución en la adopción de decisiones, de tal manera que la privación del sufragio debe ser algo excepcional y no automático a la declaración de incapacidad, que requiere además de un examen particularizado y adaptado a las circunstancias personales que concurran, exigiéndose la evaluación en cada caso de la capacidad para emitir el voto y la justificación individualizada de la privación del sufragio (Sentencias del TS de 24 de julio de 2013 y de 1 de julio de 2014).

La ausencia de criterios legales sobre dicha evaluación otorgaba inevitablemente a los jueces la concreción del nivel de capacidad necesario para el ejercicio de este derecho («test de capacidad»). En este sentido, la Sentencia del TS de 17 de marzo de 2016 señalaba que el demandante carece de la «habilidad para conocer la realidad política y discernir de forma suficiente a quién otorgar el voto (...) no basta en definitiva la voluntad, el querer votar que se patentizó en la vista, sino que es preciso que se cuente con el bagaje de conocimientos y capacidades vitales que permitan que el voto sea fruto de una decisión libre e informada, ajena por otra parte a hipotéticas influencias sobre una débil capacidad de autodeterminación $»^{17}$.

16 León Alonso M., «Los derechos de participación política de las personas con discapacidad: el derecho de voto», op. cit. p. 180.

17 En parecidos términos se pronunciaba también la STS de 3 de junio de 2017. Extraemos la cita de esta jurisprudencia del trabajo de Arnaldo Alcubilla E., «La reforma del art. 3 de la LOREG: el reconocimiento del derecho de sufragio para todas las personas con la capacidad modificada», El Consultor de los Ayuntamientos y de los Juzgados: Revista técnica especializada en Administración local y justicia municipal, núm. 
El desarrollo de la jurisprudencia del Tribunal Supremo ha dado lugar a una prolija jurisprudencia por parte de las Audiencias Provinciales. Al respecto resulta paradigmática la Sentencia de la Audiencia Provincial de Valladolid de 31 de mayo de 2017, la cual llega la conclusión de que el demandante posee «un conocimiento general y básico de la situación política actual. Ha declarado conocer a los dos partidos políticos con mayoría parlamentaria. Ha explicado, aunque no recuerda en concreto el nombre del Alcalde de Valladolid, que dicho Consistorio está regido por un gobierno tripartito. Sabe el nombre del Presidente del Gobierno de la Nación. El médico forense ha informado que sabe lo que significa votar pues sirve para formar gobiernos y que muestra habilidades y capacidad aceptables para votar pues conoce que si se decanta por una opción política no puede hacerlo por otra. Y conoce la mecánica y finalidad del proceso electoral y distingue entre las dos Cámaras Legislativas».

Finalmente, en un sentido más aperturista y moderado, la Sentencia de la Audiencia Provincial de Barcelona, de 27 de mayo de 2016, declaraba que «el derecho de participación política no puede sufrir discriminación alguna por razón de enfermedad mental, ni puede un juez establecer un estándar de exigibilidad de capacidades cognitivas e intelectivas superiores a las que sean predicables en cualquier ciudadano para impedir el ejercicio del derecho de voto, de manera que sólo razones muy específicas, motivadas y justificadas en el interés del presunto incapaz o en razones de orden público pueden legitimar una limitación del derecho de sufragio activo». Asimismo destaca la Sentencia de la Audiencia Provincial de la Rioja, de 5 de febrero de 2018, en la que se defendía que «no puede entrarse a analizar el grado de comprensión o análisis de la vida política que tiene una persona, por obedecer a criterios muy subjetivos. Lo que debe ponderar es si su afectación es tal que pudiera afirmarse que carece de voluntad como para emitir el voto. El que no se interesa por la política, o no quiera votar, no implica que no tenga derecho a hacerlo, ni por lo tanto que deba limitarse un derecho político del ciudadano» ${ }^{18}$.

Esta sentencia venía a defender que la exigencia de un «test de capacidad electoral» para el ejercicio del derecho de voto no puede servir para justificar la privación de este derecho a las personas con discapacidad intelectual, ni para

extraordinario 2, 2019, p. 35. Este planteamiento ya se había puesto de relieve en la Sentencia de la Audiencia Provincial de Ciudad Real, de 24 de octubre de 2012, que mantenía que «lo esencial no es el conocimiento o no de nuestras bases constitucionales sino la capacidad para decidir, elegir u optar libremente y sin influencias externas en un determinado proceso electoral (...) dicho ejercicio solo requiere una manifestación de voluntad, para la que resulta necesaria no tanto un determinado nivel de raciocinio o de conocimiento, sino la expresión de una opinión o decisión personal sobre las diversas ofertas electorales, en función de la formación cultural de cada persona» (Citado por Martínez-Pujalte A.L., «Derechos fundamentales y discapacidad», Comité Español de Representantes de Personas con Discapacidad (CERMI), Colección Convenio ONU, 2014, p. 93).

18 Sentencia citada por Arnaldo Alcubilla E., «La reforma del art. 3 de la LOREG: el reconocimiento del derecho de sufragio para todas las personas con la capacidad modificada», op. cit. p. 35, en la cual se enumera un importante número de recientes Sentencias de distintas Audiencias. 
restringirlo más allá de lo razonable mediante unos requisitos adicionales que no son exigidos al resto de personas sin discapacidad ${ }^{19}$.

\section{Compatibilidad constitucional}

Tras analizar el alcance y la aplicación del art. 3 de la LOREG, con anterioridad a su reforma, convendría determinar si el mismo resulta compatible con la Constitución. El punto de inflexión, a este respecto, vino dado por el Auto del TC 196/2016, de 28 de noviembre, cuyo contenido pasamos a comentar ${ }^{20}$.

Este Auto desestimó el recurso de súplica del Ministerio Fiscal contra la inadmisión del recurso de amparo formulado contra la Sentencia del Tribunal Supremo de 17 de marzo de 2016. Una sentencia que venía a ratificar lo dicho por el juzgador de instancia que privaba del derecho de sufragio activo a una persona discapacitada.

La posición mantenida por el TC se sustenta en que el derecho fundamental contenido en el art. $23 \mathrm{CE}$ es un derecho de configuración legal, de manera que la participación de los ciudadanos en los asuntos públicos ha de sustanciarse en los términos del legislador ${ }^{21}$.

Esto explica, como consecuencia lógica, que el TC no vea incompatibilidad alguna entre el ejercicio del derecho y su posible privación en casos tasados legalmente y bajo garantía judicial. El TC entiende que si concurren circunstancias que impiden su normal ejercicio, se estaría satisfaciendo no sólo el adecuado ejercicio individualizado del derecho sino también el interés general que supone la conformación racional de la voluntad política del cuerpo electoral.

El TC parece optar en su razonamiento por una «teoría del voto adecuadamente ejercitado», de tal manera que cabrían excepciones a su ejercicio cuando la persona afectada no esté en condiciones de emitir su voto y, sobre todo, de poder conformar con el raciocinio necesario el sentido del mismo.

19 PAdilla Durán hace mención a esta cuestión refiriéndose a la denominada «Herramienta de Evaluación de competencia para votar» (...) «cuyo objetivo sería crear un estándar de verificación de condiciones individualizables de la persona con discapacidad para determinar la viabilidad o no de conocer la voluntad y consciencia para entender la circunstancias y alcances de su ejercicio del sufragio activo». («Interdicción por discapacidad mental y derecho al sufragio activo», Revista Derecho Electoral, n. ${ }^{\circ} 22,2016$, p. 111).

20 Sobre esta materia puede verse a Gómez-Riesco TABERnERno DE PAZ J., «La privación del ejercicio de derecho de sufragio activo de las personas con la capacidad modificada judicialmente. Comentario al Auto del Tribunal Constitucional 196/2016, de 28 de noviembre», Revista Derecho Privado y Constitución, n. 31, 2017, pp. 243 a 274; y Varela Autrán B., «Comentario al Auto del Tribunal Constitucional de 28 de noviembre de 2016, por el que se desestima recurso de súplica planteado por el Ministerio Fiscal frente a la inadmisión de un recurso de amparo en materia del derecho de sufragio activo de una persona discapacitada», Diario La Ley, n. ${ }^{\circ} 8925,2017$.

21 Este argumento ya fue expuesto, entre otras, por la STC 153/2014, de 25 de septiembre, en la que se afirmaba que debe ser el legislador quien concrete las condiciones de la titularidad y el ejercicio del derecho de sufragio, sin menoscabar por ello el contenido esencial de este derecho. 
A ello añade que el art. 3 de la LOREG no incurre en discriminación alguna, dado que no está privando, de modo general, el derecho de voto de los discapacitados, sino que atribuye la posible limitación individualizada de dicho ejercicio a los jueces. Es decir, la privación de este derecho no se aplica a las personas con discapacidad, sino tan sólo a aquellas que, tras el oportuno proceso y con las debidas garantías judiciales, se entiende que no están en condiciones de poder ejercitarlo.

La decisión del TC, contenida en el Auto que venimos comentando, fue objeto de un voto particular formulado por la magistrada Dña. Adela Asua, la cual defendía que el art. 23 CE no condiciona el ejercicio del derecho a la posesión de un determinado nivel de conocimiento o competencias sobre el sistema político y electoral. La exigencia de un «test de capacidad» para los discapacitados constituiría un obstáculo adicional para que estas personas puedan participar de manera plena y efectiva en la vida política y social, tal y como demanda el art. 9.2 CE.

En coherencia con este planteamiento, la magistrada disidente concluye que existe una clara incompatibilidad entre la normativa española, contenida en la LOREG, y la Convención Europea de Derechos Humanos.

En nuestra opinión, el ATC 196/2016, en consonancia con el voto particular discrepante, debió haber admitido el recurso de amparo interpuesto por la demandante contra la Sentencia del TS. Es más, el TC debería haber aprovechado dicha admisión para platear una «autocuestión de inconstitucionalidad» al Pleno, al objeto de pronunciarse sobre la constitucionalidad del art. 3 de la $\mathrm{LOREG}^{22}$. Y es que si cualquier restricción legal al ejercicio de un derecho fundamental debe ser proporcional y estar suficientemente motivada, cuando se trata de la participación de una parte del cuerpo electoral en la conformación libre de la voluntad popular, dicha justificación adquiere un peso específico que hubiera meritado el pronunciamiento del TC sobre la exigencia de requisitos adicionales al colectivo de personas discapacitadas a la hora de ejercer el derecho de sufragio.

La entrada en juego del ejercicio legítimo de un derecho fundamental, vinculado estrechamente a la dignidad humana y al libre desarrollo de la personalidad, convierte cualquier requisito adicional e injustificado en una categoría sospecha de discriminación que afecta, además, a un colectivo especialmente vulnerable histórica y socialmente.

El primer paso para conseguir la plena integración de las personas discapacitadas requiere, por tanto, el pleno reconocimiento legal del derecho de sufragio activo, tal y como ha sucedido tras la reforma de la LOREG.

22 Seguimos el planteamiento de CuEnCa Gómez P., «El derecho al voto de las personas con discapacidad intelectual y psicosocial...», op. cit. p. 195. 


\section{ALGUNAS CONSIDERACIONES PRELIMINARES SOBRE LA REFORMA DE LA LOREG DE 2018}

La falta de ajuste entre la normativa internacional y la LOREG hizo que el Grupo Parlamentario Mixto presentara, el 14 de febrero de 2017, una Proposición de Ley de modificación del art. 3 de la LOREG, sobre el derecho de sufragio de las personas incapacitadas o internadas judicialmente ${ }^{23}$.

Con posterioridad a esta proposición, que no prosperó, se presentó otra iniciativa legislativa por la Asamblea de Madrid, el 5 de septiembre de 2017, que sí fue tomada en consideración por unanimidad de los 343 miembros presentes en la sesión del Pleno del Congreso de los Diputados de 7 de noviembre del mismo año ${ }^{24}$, y que finalmente se materializó en la Ley $2 / 2018$, de 5 de diciembre.

El motivo de esta modificación legal radica, en opinión de los proponentes y según consta en la Exposición de Motivos, en la Recomendación 48. ${ }^{a}$ formulada en 2011 por el Comité de la ONU sobre los Derechos de las Personas con Discapacidad $^{25}$, en la que se apuntaba hacia la revisión de «toda la legislación pertinente para que todas las personas con discapacidad, independientemente de su deficiencia, de su condición jurídica o de su lugar de residencia, tengan derecho a votar y a participar en la vida pública en pie de igualdad con los demás».

A raíz de esta propuesta de reforma, la Comisión Constitucional del Congreso de los Diputados acordó, el 10 de octubre de $2018^{26}$, la supresión de los apartados b) y c) del art. 3.1 de la LOREG, proponiendo la siguiente redacción para el art. 3.2: «Toda persona podrá ejercer su derecho de sufragio activo, consciente, libre y voluntariamente, cualquiera que sea su forma de comunicarlo y con los medios de apoyo que requiera ${ }^{27}$.

La Ley 2/2018, de 5 de diciembre, para garantizar el derecho de sufragio de todas las personas con discapacidad, va en la línea de la Ley 51/2003, de 2 de

23 BOCG, n. ${ }^{\circ} 87-1$, de 17 de febrero de 2017.

24 BOCG, n. ${ }^{\circ}$ 150-1, de 8 de septiembre de 2017 y DSCD, n. ${ }^{\circ} 87$, de 7 de noviembre de 2017 , respectivamente.

25 En relación con este asunto resultan llamativo los datos ofrecidos por el Comité Económico y Social Europeo en un Documento Informativo, aprobado por el Pleno de este órgano el 20 de marzo de 2019, bajo el Título: «El derecho real de voto en las elecciones al Parlamento Europeo de las personas con discapacidad». Entre dichos datos destacan los siguientes: a) En virtud de las distintas regulaciones nacionales, unos 800.000 ciudadanos de 16 Estados miembros de la Unión Europea, se ven privados de su derecho a participar en unas elecciones debido a su discapacidad o problema de salud mental. b) En los ordenamientos jurídicos de nueve países la gran mayoría de personas bajo tutela son excluidas del derecho de participación política y privadas del derecho de voto. c) En siete Estados miembros, en cambio, el establecimiento de algún mecanismo de tutela sobre una persona no conlleva la pérdida automática del derecho de voto. Admitiéndose la posibilidad específica de que un tribunal pueda privar al tutelado del derecho de sufragio. d) En once Estados miembros, entre los que se incluiría España, no se podría privar a una persona con discapacidad del derecho de sufragio activo.

26 DSCD, n. ${ }^{\circ} 620$, de 10 de octubre de 2018 y BOCG, n. ${ }^{\circ} 150-6$, de 18 de octubre de 2018.

27 Sobre las deficiencias de esta nueva regulación legislativa puede verse a PÉrEz AlBERdi M. ${ }^{a}$.R., «Los derechos de participación política de las personas con discapacidad», Lex Social, Volumen 9, n. ${ }^{\circ}$ 1, 2019, pp. 83 a 107. 
diciembre, de Igualdad de Oportunidades, no Discriminación y Accesibilidad Universal de las Personas con Discapacidad, cuyo art. 1.1 dispone «la ausencia de discriminación, directa o indirecta, que tenga su causa en una discapacidad, así como la adopción de medidas de acción positiva orientadas a evitar o compensar las desventajas una persona con discapacidad para participar plenamente en la vida política, económica, cultural y social». Así como del Real Decreto Legislativo $1 / 2013$, de 29 de noviembre, por el que se aprueba el Texto Refundido de la Ley General de Derechos de las Personas con Discapacidad y de su Inclusión Social, cuyo art. 53 señala que «las personas con discapacidad podrán ejercer el derecho de participación en la vida política y en los procesos electorales en igualdad de condiciones que el resto de ciudadanos conforme a la normativa en vigor».

Por mandato de la reformada Disposición Adicional Octava de la LOREG, «las personas a las que se hubiere limitado o anulado su derecho de sufragio por razón de discapacidad quedan reintegradas plenamente en el mismo por ministerio de la ley», lo que significa que el legislador deja sin efectos todas las resoluciones judiciales anteriores que declaraban la discapacidad de las personas, así como las correspondientes inscripción de las mismas en el Registro Civil.

En lugar de esta suerte de «amnistía electoral» debería haberse apostado por un sistema individualizado de revisión sentencias, o bien por un sistema integral para propiciar que dicho colectivo pueda ejercer sus derechos de participación política. En todo caso, esta reintegración de derechos plantea una interesante problemática a la hora de interpretar el alcance del art. 3.1 LOREG, cuando habla del ejercicio del sufragio activo de forma «consciente, libre y voluntaria».

Ante la ausencia de previsiones legales y jurisprudenciales al respecto, la Junta Electoral Central aprobó la Instrucción 5/2019, de 11 de marzo, sobre la aplicación de la modificación de la LOREG llevada a cabo por la Ley 2/2018, de 5 de diciembre.

El punto segundo de la mencionada Instrucción establecía que «las mesas electorales deberán admitir el voto del cualquier persona con aparente discapacidad que se encuentre inscrita en el censo electoral correspondiente (...) en el supuesto de que algún miembro de una mesa electoral, o alguno de los interventores o apoderados adscritos a esa mesa considere que el voto de una persona con discapacidad no es ejercido de forma consciente, libre y voluntaria, lo podrá hacer constar en el acta de la sesión, pero no impedirá que dicho voto sea introducido en la urna».

Con independencia de la desafortunada redacción de esta Instrucción, que habla de «aparente discapacidad» y «voto de una persona con discapacidad», expresiones que fueron suprimidas por la Instrucción 7/2019, de 18 de marzo, resulta del todo punto paradójico que la Junta Electoral Central intente suplir las lagunas del legislador, cuando su función consiste en unificar los criterios interpretativos de las Juntas Electorales Provinciales en la aplicación de la normativa electoral, según prevé el art. 19.1 f. LOREG.

En la exposición de motivos de ambas Instrucciones se afirma que el ejercicio «consciente, libre y voluntariamente» del derecho de sufragio activo «suscita 
problemas interpretativos que no han quedado resueltos por el legislador», de tal manera, y «en tanto el legislador no establezca ninguna concreción a estas cuestiones, ante la cercanía de varios procesos electorales, la Junta Electoral Central considera que resulta necesario clarificar estos extremos y fijar unos criterios que puedan seguir los diferentes sujetos afectados».

Y para ello, la Junta Electoral Central erige a las mesas electorales en el órgano de garantía del ejercicio consciente, libre y voluntario del derecho de voto, atribuyéndoles una tarea que, además de generar un importante grado de inseguridad jurídica, con el consiguiente riesgo para el pleno y efectivo ejercicio de dicho derecho, no les corresponde, dado que el art. 85.4 LOREG tan sólo encomienda a la Mesa electoral la verificación de la identidad de los votantes.

\section{CONCLUSIONES}

La evolución lógica y natural del derecho de participación política debe encuadrarse en el marco de una sociedad democrática avanzada, que contemple estas situaciones desde una lógica integrativa, inclusiva e igualitaria, al objeto de hacer efectiva la proclamación teórica del pleno ejercicio y disfrute de los derechos fundamentales y libertades públicas.

Y es que el «derecho de voto va más allá de la privacidad y se convierte en un derecho público, de naturaleza política y cuya expresión, derecho de voto en elecciones libres, tiene una profunda conexión con lo que supone la exigencia de un principio democrático y una sociedad articulada y vertebrada desde la igualdad y la participación de personas libres en la elección de sus representantes $»^{28}$.

La maximización en el ejercicio de los derechos fundamentales, unido a la evolución de la perspectiva proteccionista de las personas con alguna discapacidad intelectual, debe llevarnos a concluir que la incapacidad no implica, en principio, la privación de ningún derecho fundamental o libertad pública, sino que debe «implementarse una concepción progresiva y garantista donde se presuma la universalidad del derecho fundamental al sufragio directo, en específico para las personas con discapacidad mental» ${ }^{29}$.

La vertiente objetiva de los derechos fundamentales y su efectivo ejercicio irradian un efecto institucional y social que trasciende las circunstancias personales de los sujetos afectados y el ejercicio individualizado de las facultades inherentes.

28 López-Medel BÁscones J., «El derecho a voto de las personas con discapacidad», Revista de las Cortes Generales, n. ${ }^{\circ} 85,2012$, p. 179.

29 PAdilla Durán D.A., «Interdicción por discapacidad mental y derecho de sufragio activo», op. cit. p. 114 . 
La conformación política de la voluntad del cuerpo electoral sólo puede satisfacerse, en definitiva, si todos los colectivos de ciudadanos pueden participar activamente en los asuntos de la comunidad.

La incompatibilidad de estos argumentos con la normativa electoral española y, sobre todo, con los criterios empleados por algunos tribunales a la hora de exigir un «test de capacidad electoral» para las personas discapacitadas, hizo que en 2018 se modificara la normativa española en la materia. Una reforma oportuna y pedagógica aunque imprecisa e insuficiente, que requiere ser implementada legal y constitucionalmente; de aquí la necesidad de proseguir con la proyectada reforma del art. $49 \mathrm{CE}$.

En dicha reforma el legislador plantea, como decimos, un «escenario de incertidumbre» dado que reconoce el derecho de sufragio activo a cualquier persona, pero matiza que el contenido esencial del derecho de sufragio activo consiste en la emisión del voto de forma consciente, libre y voluntaria. La pregunta, por tanto, que surge de inmediato es en qué términos y a quién corresponderá garantizar dicho contenido esencial ${ }^{30}$.

La reforma de la LOREG, en definitiva, resuelve el problema de la titularidad del derecho de sufragio activo por las personas con discapacidad intelectual, pero no termina de concretar la fórmula para garantizar el adecuado ejercicio del mismo, no sólo para estas personas sino para cualquiera que se encuentre en la tesitura de no poder emitir su voto de forma «consciente, libre y voluntaria».

TITLE: Reality and perspective of the right of suffrage of persons with intellectual disabilities

ABSTRACT: The overcoming of the protectionist model by a progressive extension of the full enjoyment of the rights of disabled people has generated, at least in the Spanish case, some dysfunctions not exempt from controversy. With the reform of the LOREG of 2018, it has gone from a system in which the judge determined in each case the degree of "political capacity» of the disabled person, to another where the legislator liberalizes the exercise of active suffrage, leaving in the air some aspects, related to the conditions and limits of this exercise, which generate a certain legal uncertainty.

RESUMEN: La superación del modelo proteccionista por una progresiva extensión del pleno disfrute de derechos de las personas discapacitadas ba generado, al menos en el caso español, algunas disfuncionalidades no exentas de polémica. Con la reforma de la LOREG de 2018, se ha pasado de un sistema en el que el juez determinaba en cada caso el grado de «capacidad política» de la persona discapacitada, a otro donde el

30 Como sostiene Arnaldo Alcubilla: «por ministerio de la ley los privados del derecho de sufragio lo recuperan de forma automática, sean cuales sean las circunstancias y su previa reevaluación por el juez. Una ley, pues, anula resoluciones judiciales firmes, hecho realmente insólito en nuestro ordenamiento jurídico que pretende justificarse en la garantía de la plena efectividad de los derechos de las personas con discapacidad, aunque realmente — reiteramos — son incapacitadas (...) Y, en todo caso, en los nuevos procedimientos de que conozcan han de obviar cualquier pronunciamiento sobre el derecho de sufragio de las personas para las que se demanda la modificación de la capacidad de obrar» («La reforma del art. 3 de la LOREG: el reconocimiento del derecho de sufragio para todas las personas con la capacidad modificada», op. cit. p. 38). 
legislador liberaliza el ejercicio del sufragio activo, dejando en el aire algunos aspectos, relativos a las condiciones y límites de dicho ejercicio, que generan una cierta inseguridad jurídica.

KEY WORDS: Disability, exercise of rights, active suffrage.

Palabras Clave: Discapacidad, ejercicio de derechos, sufragio activo.

FECHA DE RECEPCión: 04.06.2019 FECHA DE ACEPTACión: 11.09.2019 
